Vol..5, No.2, 2019

Doi: https://doi.org/10.24198/cosmogov.v5i2.21814

http://jurnal.unpad.ac.id/cosmogov/index

\title{
COLLABORATIVE GOVERNANCE MELALUI PROGRAM KAMPUNG KB DI KABUPATEN JOMBANG
}

\author{
Novy Setia Yunas ${ }^{1}$ dan Faza Dhora Nailufar ${ }^{2}$ \\ ${ }^{\text {I} P r o g r a m ~ S t u d i ~ I l m u ~ P o l i t i k, ~ F a k u l t a s ~ I l m u ~ S o s i a l ~ d a n ~ I l m u ~ P o l i t i k, ~ U n i v e r s i t a s ~ B r a w i j a y a ~ M a l a n g ~}$ \\ $\mathrm{Jl}$. Veteran Malang, Ketawanggede, Kec. Lowokwaru, Kota Malang, Jawa Timur 65145, Indonesia \\ Email: novysetiayunas@gmail.com \\ ${ }_{2}^{2}$ Sekolah Tinggi Ilmu Administrasi Lembaga Administrasi Negara Jakarta \\ Jalan Veteran No.10, Gambir, RT.2/RW.3, Gambir, Kecamatan Gambir, Kota Jakarta Pusat, \\ Daerah Khusus Ibukota Jakarta 10110, Indonesia \\ Email: fazadhoran@gmail.co.id
}

Submitted: June 20, 2019, Reviewed: November 4, 2019, Published: November 27, 2019

\begin{abstract}
ABSTRAK
Salah satu program prioritas dalam Nawacita adalah KKBPK (Kependudukan Keluarga Berencana dan Pembangunan Keluarga. Tulisan ini akan mengubas program Kampung KB vang merubakan imnlementasi program KKBPK. Program Kamnung KB merunakan program vang didesain sebagai program nemberdavaan masvarakat vang bersifat kolaboratif karena selain bisa mengentaskan kemiskinan. mendekatkan pembangunan kepada masyarakat juga melibatkan semua sektor pembangunan. Melalui pendekatan deskriptif kualitatif dengan metode eksplorasi, tulisan ini akan memfokuskan pada implementasi program Kampung KB di Kabupaten Jombang. Hasilnya, secara umum keberadaan Kampung KB berkontribusi secara signifikan pada penguatan program KKBPK. Kolaborasi antara Pemerintah Kabupaten, Pemerintah Desa, CSO, Sektor swasta dan masyarakat menghasilkan kekuatan besar yang membuat program ini dapat mencapai tujuan yang telah ditetapkan, walaupun tidak bisa dipungkiri masih terdapat beberapa kendala dalam anggaran dan fungsi koordinatif. Oleh karena itu solusi yang ditawarkan dalam tulisan ini berupa penguatan anggaran serta dibentuknya forum yang bisa menjadi wadah koordinasi bagi semua pihak terkait untuk selalu berkoordinasi dan melakukan evaluasi.
\end{abstract}

Kata Kunci: Kampung KB, Collaborative Governance, Kabupaten Jombang, Pemberdayaan

\begin{abstract}
One of the priority programs in Nawacita is KKBPK ( The Population Family Planning and Family Development). This paper will explore the Kampung $\mathrm{KB}$ program which is the implementation of the KKBPK program. Kampung KB program is designed as a community empowerment program that is collaborative because in addition to alleviating poverty, bringing poverty closer development to the community also involves all development sectors.Through a qualitative descriptive approach with exploratory methods, this paper will focus on the implementation of the Kampung KB program in Jombang District, as a result, in general the existence of the KB Village contributes significantly to strengthening the KKBPK program. The village government, CSOs, the private sector and the community produced a great power that made the program achieve its stated goals, although it is undeniable that there are still some constraints in the budget and coordinating functions. Therefore the solution offered in this paper is in the form of strengthening the budget and the formation of a forum that can be a coordinating forum for all parties concerned to always coordinate and evaluate.
\end{abstract}

Keywords: Kampung KB, Collaborative Governance, Jombang District, Empowerent 
Vol..5, No.2. 2019

Doi: https://doi.org/10.24198/cosmogov.v5i2.21814

http://jurnal.unpad.ac.id/cosmogov/index

\section{PENDAHULUAN}

Kampung KB merupakan program yang dicanangkan Presiden Joko Widodo sebagai wujud dari agenda prioritas pembangunan Nawacita periode 20152019. Program tersebut merupakan implementasi dari tiga agenda prioritas sekaligus yakni agenda prioritas ke-3 Membangun Indonesia dari Pinggiran dengan Memperkuat Daerah-Daerah dan Desa dalam kerangka Negara Kesatuan Republik Indonesia, agenda prioritas ke-5 Meningkatkan Kualitas Hidup Manusia Indonesia, serta agenda prioritas ke-8 Revolusi Karakter Bangsa melalui Pembangunan Kependudukan dan Keluarga Berencana. Pembentukan kampung KB yang digunakan sebagai solusi untuk menekan angka pertumbuhan penduduk dan bertujuan untuk meningkatkan kesejahteraan rakyat Indonesia.

Program kampung KB merupakan salah satu realisasi dari upaya pemerintah untuk meningkatkan kualitas hidup masyarakat sesuai dengan indikator pencapaian program Kependudukan Keluarga Berencana dan Pembangunan Keluarga (KKBPK). Ketercapaian program ini dapat dinilai dari beberapa aspek yaitu aspek pengendalian kuantitas penduduk dan aspek peningkatan kualitas penduduk yang dalam hal ini diukur dengan peningkatan ketahanan dan kesejahteraan keluarganya. Aspek kedua ini dapat dinilai dari beberapa indikator yakni peningkatan pengguna KB baru, peningkatan jumlah ibu hamil dan menyusui yang mendapatkan pelayanan kesehatan, peningkatan jumlah remaja yang aktif dalam kegiatan Bina Keluarga Remaja (BKR) dan Pusat Informasi dan Konseling Kesehatan Reproduksi Remaja (PIK-R), penurunan jumlah perempuan yang buta aksara, peningkatan partisipasi keluarga pra sejahtera dan KS-1 dalam Usaha Peningkatan Pendapatan Keluarga Sejahtera (UPPKS). Indikator-indikator tersebut merupakan breakdown dari 8 fungsi keluarga seperti yang tercantum pada Peraturan Pemerintah No 87 Tahun 2014 tentang Perkembangan Kependudukan dan Pembangunan Keluarga, Keluarga Berencana dan Sistem Informasi Keluarga. Dalam Peraturan tersebut disebutkan bahwa 8 fungsi keluarga meliputi: (1) fungsi keagamaan, (2) fungsi sosial budaya, (3) fungsi cinta kasih, (4) fungsi perlindungan, (5) fungsi reproduksi, (6) fungsi sosialisasi dan pendidikan, (7) fungsi ekonomi dan (8) fungsi pembinaan lingkungan.

Bukan hanya dalam konsep, pada implementasinya pun kebijakan Kampung KB harus melibatkan banyak pihak, mulai dari pemerintah dari semua level (Pemerintah Kabupaten, Kecamatan, Desa dan Dusun), masyarakat sipil beserta organisasi yang ada serta sektor swasta. Oleh karena itu, dalam makalah ini akan dijelaskan implementasi konsep Collaborative Governance dalam kebijakan Kampung KB di Kabupaten Jombang mengingat masih banyak Kampung KB yang belum dapat berjalan secara maksimal dikarenakan belum ada sinergi antar beberapa pihak yang berkaitan, yakni pemerintah, masyarakat sipil serta sektor swasta. 
Vol..5, No.2. 2019

Doi: https://doi.org/10.24198/cosmogov.v5i2.21814

http://jurnal.unpad.ac.id/cosmogov/index

\section{Collaborative Governance}

\section{Collaborative}

Governance

merupakan pengembangan dari konsep Governance yang bertujuan pada ketercapaian tujuan serta efektifitas pembangunan. Collaborative Governance didefinisikan oleh Ansell dan Gash (2007:544) sebagai sebuah pengaturan yang mengatur satu atau lebih lembaga publik secara langsung agar terlibat dengan pemangku kepentingan non publik dalam proses pengambilan keputusan kolektif yang bersifat formal, berorientasi pada konsensus, dan musyawarah yang bertujuan untuk membuat atau mengimplementasikan kebijakan publik atau mengelola program atau aset publik. Sedangkan Agrawal dan Lemos (2007) (dalam Balogh, S, dkk, 2011:3) menjelasakan bahwa Collaborative Governance merupakan implementasi dari adanya konsep "multipatrner governance" yang meliputi sektor privat, masyarakat dan komunitas sipil dan terbangun atas sinergi peran stakeholder dan penyusunan rencana yang bersifat hybrid seperti halnya kerjasama public-privat dan privat-sosial.

Lebih terperinci, Dwiyanto (2015) menjelaskan bahwa dalam kerjasaman kolaboratif terjadi penyampaian visi, tujuan, strategi, dan aktivitas masingmasing pihak yang berkaitan. Tetapi mereka tetap memiliki otoritas untuk mengambil keputusan secara independen dalam mengelola organisasinya walaupun merka tunduk pada kesepakatan bersama. Senada dengan definisi yang disampaikan Dwiyanto, Sink mendefinisikan Collaborative Governance sebagai proses dimana organisasi-organisasi yang memiliki kepentingan terhadap suatu masalah tertentu berusaha mencari solusi bersama dalam rangka mencapai tujuan yang tidak bisa mereka capai sendirisendiri. Tujuan mereka terfokus pada penyelesaian masalah secara bersamasama. Lebih lanjut dijelaskan bahwa pihak yang melakukan kesepakatan bersama tersebut tidak terbatas pada instansi pemerintah dan non pemerintah saja, namun terdapat pelibatan masyarakat sipil dalam perumusan dan pengembilan keputusan. Inisiasi kolaborasi didasarkan atas keterbatasan kapasitas, sumber daya maupun jaringan yang dimiliki masingmasing pihak, sehingga kerjasama dapat saling melengkapi dan mendorong keberhasilan pencapaian tujuan bersama.

Definisi-defini diatas setidaknya telah menunjukkan bahwa konsep Collaborative Governance merupakan konsep pembangunan yang bertumpu pada ketiga pilar demokrasi yakni pemerintah, sektor swasta/private dan masyarakat sipil. Nilai lebih dari pendekatan ini dapat dilihat dari pelibatan aktif masyarakat sipil dan atau sektor swasta yang merupakan objek pembangunan.

Pendekatan Collaborative Governance ini dianggap tepat untuk menjelaskan implementasi program Kampung KB di kabupaten Jombang karena dalam pelaksanaannya terdapat pelibatan aktif bukan hanya beberapa instansi pemerintah, namun juga masyarakat sipil.

\section{Kampung KB}

Kampung KB merupakan satuan wilayah setingkat RW, dusun atau setara, 
Vol..5, No.2, 2019

Doi: https://doi.org/10.24198/cosmogov.v5i2.21814

http://jurnal.unpad.ac.id/cosmogov/index

yang memiliki kriteria tertentu, dimana terdapat keterpaduan program kependudukan, keluarga berencana, pembangunan keluarga dan pembangunan sektor terkait yang dilaksanakan secara sistemik dan sistematis. Secara umum tujuan didirikannya Kampung $\mathrm{KB}$ ini adalah sebagai sarana peningkatan kualitas hidup masyarakat di tingkat kampung atau yang setara, melalui program kependudukan, keluarga berencana dan pembangunan keluarga serta pembangunan sektor terkait dalam rangka mewujudkan keluarga kecil berkualitas (BPS, 2017). Sedangkan tujuan khususnya yaitu

Peningkatan peran pemerintah,baik pusat maupun daerah, lembaga non pemerintah dan swasta dalam memfasilitasi, mendampingi serta membina masyarakat untuk menyelenggarakan program kependudukan, keluarga berencana, pembangunan keluarga dan pembangunan sektor terkait.

1. Sebagai sarana peningkatan kesadaran masyarakat tentang pembangunan yang berwawasan kependudukan.

2. Peningkatan jumlah peserta $\mathrm{KB}$ aktif modern.

3. Peningkatan ketahanan keluarga melalui program Bina Keluarga Balita, Bina Keluarga Remaja, Bina Keluarga Lansia, serta Pusat Informasi dan Konseling Remaja.

4. Peningkatan pemberdayaan keluarga melalui Kelompok UPPKS

5. Penurunan angka KDRT.
6. Peningkatan derajat kesehatan masyarakat.

7. Peningkatan rata-rata lama sekolah penduduk usia sekolah.

8. Serta peningkatan sarana dan prasarana pembangunan kampung (BKKBN, 2016).

Secara substansi terdapat tiga hal pokok yang dapat dijadikan bahan pertimbangan apakah suatu daerah layak dicanangkan sebagai Kampung KB atau tidak, yaitu : pertama, ketersediaan data kependudukan yang akurat; kedua, dukungan dan komitmen Pemerintah Daerah serta ketiga, terdapat partisipasi aktif masyarakat. Selain itu terdapat pula kriteria untuk menentukan apakah suatu wilayah cukup relevan untuk dicanangkan sebagai lokasi Kampung KB atau tidak, yaitu : Kriteria pertama mencakup dua hal, yaitu: (1) Jumlah Keluarga Pra Sejahtera dan KS 1 (miskin) di atas rata-rata Pra Sejahtera dan KS 1 tingkat desa/kelurahan di mana kampung tersebut berada, (2) jumlah peserta KB di bawah rata-rata pencapaian peserta $\mathrm{KB}$ tingkat desa/kelurahan di mana kampung KB tersebut berlokasi. Sedangkan untuk kriteria wilayah:yang mencakup 10 kategori wilayah (dipilih salah satu), yaitu: (1) Kumuh, (2) Pesisir, (3) Daerah Aliran Sungai (DAS), (4) Bantaran Kereta Api, (5) Kawasan Miskin (termasuk Miskin Perkotaan), (6) Terpencil, (7) Perbatasan, (8) Kawasan Industri, (9) Kawasan Wisata, (10) Padat Penduduk. Selanjutnya dalam menentukan kriteria wilayah yang akan dijadikan sebagai lokasi pembentukan Kampung KB dapat dipilih satu atau lebih dari sepuluh kriteria yang ada. Kriteria 
Vol..5, No.2, 2019

Doi: https://doi.org/10.24198/cosmogov.v5i2.21814

http://jurnal.unpad.ac.id/cosmogov/index

Khusus pembentukan Kampung KB yang mencakup 5 hal, yaitu: (1) kriteria data di mana setiap RT/RW memiliki Data dan Peta Keluarga, (2) kriteria kependudukan di mana angka partisipasi penduduk usia sekolah rendah, (3) kriteria program KB di mana peserta KB Aktif dan Metode Kontrasepsi Jangka Panjang (MKJP) lebih rendah dari capaian rata-rata tingkat desa/kelurahan serta tingkat unmet need lebih tinggi dari rata-rata tingkat desa/kelurahan, (4) kriteria program pembangunan keluarga di mana partisipasi keluarga dalam pembinaan ketahanan keluarga, pemberdayaan ekonomi dan partisipasi remaja dalam kegiatan GenRe melalui PIK-R masih rendah, (5) kriteria program pembangunan sektor terkait yang mencakup setidaknya empat bidang, yakni kesehatan, ekonomi, pendidikan, pemukiman dan lingkungan, dan masih bisa ditambah dengan program lainnya sesuai dengan perkembangan (BKKBN, 2016).

\section{METODE PENELITIAN}

Tulisan ini merupakan saripati dari penelitian kualitatif dengan metode penelitian deskriptif. Dalam prosesnya, peneliti menggunakan teknik wawancara mendalam (indepth interview) dan observasi lapangan untuk mencari data. Selanjutnnya, data yang dihasilkan akan dianalisa secara sistematis, faktual, dan akurat. Penelitian ini mengambil lokus di 3 Desa yang dicanangkan sebagai Kampung KB di Kabupaten Jombang, yaitu Dusun, Munggut, Kec. Ngusikan; Desa. Plabuhan, Kec. Plandaan dan Desa Pulonasir, Kec. Bareng. Keempat lokasi tersebut merupakan Kampung KB pertama di Jombang yang dicanangkan pada tahun 2016 dan 2017. Selain itu, keempat lokus tersebut memiliki kesamaan karakteristik, yakni merupakan Kampung KB yang terleak di daerah terpencil, serta memiliki akses kesehatan dan pendidikan yang minim.

Teknik wawancara mendalam dan participant observasi membuat peneliti memahami apa yang sebenarnya terjadi. Peneliti dapat melakukan kroscek validasi data baik secara sengaja melalui wawancara dengan narasumber silang ataupun mendengar langsung percakapan dan cerita dari masyarakat. Selain itu data juga diperoleh dari kajian literatur yang berasal dari pemberitaan di media serta dokumen-dokumen penunjang. Pengecekan validasi data ini dilakukan disepanjang penelitian agar data yang dihasilkan lebih mendalam dan eksploratif.

\section{HASIL PENELITIAN}

\section{Implementasi Program Kampung KB} di Kabupaten Jombang

Hingga tahun 2017, hampir seluruh kecamatan di Kabupaten Jombang telah memiliki Kampung KB. Namun terdapat 4 dusun yang dicanangkan sebagai rintisan Kampung $\mathrm{KB}$, yaitu Dusun Munggut, Desa Cupak, Kecamatan Ngusikan, Dusun Sumberpelas, Desa Plabuhan, Kecamatan Plandaan, Dusun Pulonasir, Desa Pulosari, Kecamatan Bareng. Ketiga dusun ini memiliki topografi dan karakteristik yang sama pula yakni sama-sama terletak jauh dari Ibukota kecamatan dan terpencil. 
Vol..5, No.2, 2019

Doi: https://doi.org/10.24198/cosmogov.v5i2.21814

http://jurnal.unpad.ac.id/cosmogov/index

Dusun Munggut, Desa Cupak, Kecamatan Ngusikan merupakan Kampung KB yang diresmikan pada tahun 2016. Dusun ini terletak dibagian terpencil dari dusun Munggut ini merupakan satu dari dusun terluar kecamatan Ngusikan yang merupakan kecamatan dengan jarak terjauh dari pusat Kabupaten Jombang. Terletak hampir $26 \mathrm{Km}$ dari pusat kota menyebabkan kecamatan ini cenderung tertinggal dalam pembangunan fisik maupun sosial. Wilayah terluar dari kecamatan ini terletak di bagian utara kecamatan, dimana lokasi dusun Munggut berada. Oleh karena itu, posisi dusun Munggut pun bisa dikatakan sangat terpencil. Akses jalan menuju dusun ini pun relatif sulit dikarenakan topografi jalan yang curam di beberapa titik serta tekstur jalannya berbatu dan tanah yang licin dan membahayakan jika musim hujan. Fasilitas kesehatan yang terdapat di Dusun yang terletak sekitar $6 \mathrm{Km}$ dari pusat Desa (balai Desa) inipun sangat minim. Belum ada Balai Dusun dan Polindes disana, sehingga jika ada warga yang ingin mendapatkan fasilitas kesehatan, maka dia diharuskan ke Desa Cupak atau Desa lain yang letaknya juga cukup jauh. Pencanangan Dusun Munggut sebagai Kampung KB membawa dampak signifikan bagi warga Dusun Munggut itu sendiri. Tercatat sejak dicanangkan sebagai Kampung KB, infrastruktur dan akses jalan yang berada maupun yang menuju Dusun Munggut diperbaiki melalui sharing dana APBN dan APBD. Perbaikn infrastruktur ini tentunya menjadi pintu gerbang bagi pencapaian program-program KKBPK. Berikut data kegiatan yang dilakukan di Dusun Munggut pasca pencanangannya sebagai Kampung KB :

Tabel 1. Kegiatan Pasca Pencanangan Kampung KB di Dusun Munggut

\begin{tabular}{|c|c|c|c|}
\hline No & Program & Tahun & Sumber Anggaran \\
\hline 1 & $\begin{array}{l}\text { Pembinaan dan Penyuluhan KB dan } \\
\text { Tribina, PIKR, UPPKS oleh DPPKB } \\
\text { Kabupaten Jombang }\end{array}$ & 2017 & APBD \\
\hline 2 & Baksos oleh Dinas Kesehatan & 2016 & APBD \\
\hline 3 & $\begin{array}{c}\text { Penyerahan BKL Kit, BKB Kit dan } \\
\text { Genre Kit }\end{array}$ & 2017 & APBD \\
\hline 4 & $\begin{array}{c}\text { Penyerahan Bantuan Ternak } 10 \\
\text { Kambing Jantan dan } 20 \text { Kambing } \\
\text { Betina }\end{array}$ & 2017 & APBD \\
\hline 5 & Pelatihan CTU Bidan & 2016 & $\begin{array}{c}\text { APBD } \\
\text { (BKKBN Provinsi Jawa } \\
\text { Timur) }\end{array}$ \\
\hline 6 & $\begin{array}{c}\text { Obgyn Bed, Implan Kit, IUD Kit dan } \\
\text { Leaflet }\end{array}$ & 2016 & $\begin{array}{c}\text { APBD } \\
\text { (BKKBN Provinsi Jawa } \\
\text { Timur) }\end{array}$ \\
\hline 7 & Kartu KB Informed Consent & 2016 & $\begin{array}{c}\text { APBD } \\
\text { (BKKBN Provinsi Jawa } \\
\text { Timur) }\end{array}$ \\
\hline 8 & Jalan Cor & 2017 & $\begin{array}{l}\text { APBD } \\
\text { (Dinas PUPR Kabupaten } \\
\text { Jombang }\end{array}$ \\
\hline 9 & Penerangan Jalan Umum & 2017 & $\begin{array}{c}\text { APBD } \\
\text { (Dinas PUPR Kabupaten } \\
\text { Jombang }\end{array}$ \\
\hline
\end{tabular}


Vol..5, No.2, 2019

Doi: https://doi.org/10.24198/cosmogov.v5i2.21814

http://jurnal.unpad.ac.id/cosmogov/index

\begin{tabular}{|c|c|c|}
\hline 10 & Jalan Cor & $\begin{array}{c}\text { APBN } \\
\text { (Kemendes PDT) }\end{array}$ \\
\hline
\end{tabular}

Sumber : Hasil wawancara diolah

Dengan adanya bantuan-bantuan diatas, banyak fasilitas yang bisa dinikmati oleh warga di Dusun Munggut. Warga tidak peru lagi ke desa tetangga jika hendak berobat. Tenaga kesehatan pun tidak terlalu susah payah dalam melakukan tugasnya karena hampir semua fasilitas kesehatan yang dibutuhkan sudah tersedia.

Dusun kedua yang menjadi lokasi rintisan Kampung $\mathrm{KB}$ adalah Dusun Sumberpelas, Desa Plabuhan, Kecamatan Plandaan. Sama dengan Dusun Munggut, aksesibilitas menuju Dusun Sumberpelas pun relatif sulit. Jalan menuju Dusun ini sebenarnya sudah diaspal, namun mengalami kerusakan yang cukup parah. Ditambah lagi topografi wilayah di beberapa titik dengan kemiringan yang curam menyebabkan jalan semakin sulit dilalui terutama bila musim hujan. Pasca dicanangkan sebagai Kampung KB pada 2016, warga dusun yang dikelilingi hutan jati ini mengalami perubahan pola hidup yang signifikan. salah satu contohnya adalah peningkatan penggunaan akseptor KB. Lebih beruntung dari Dusun Munggut, di Dusun Sumberpelas sudah tersedia balai desa yang bisa digunakan sebagai tempat melakukan pelayanan kesehatan (polindes).

Dusun terakhir yang merupakan rintisan Kampung $\mathrm{KB}$ adalah Dusun Pulonasir, Desa Pulosari, Kecamatan Bareng. Dusun yang dicanangkan sebagai Kampung KB pada 2016 ini salah satu dusun yang cukup terpencil di Desa Pulosari. Akses menuju dusun tersebut sangat sulit, karena harus melalui hutan dan jalanan yang tak beraspal. Terdapat perubahan signifikan sebagai dampak positif dari pencanganan dusun ini sebagai Kampung KB, yaitu peningkatan penggunaan akseptor KB serta variasinya. Warga tidak lagi hanya menggunakan suntik dan pil, namun lebih variatif.

Dari implementasi Kampung KB di 3 (tiga) lokasi tersebut, dapat ditarik kesimpulan bahwa pencanangan Kampung $\mathrm{KB}$ di wilyah tersebut membawa dampak positif yang signifikan bagi warga. Tidak hanya diukur dari sekedar peningkatan penggunaan akseptor $\mathrm{KB}$, kesadaran warga akan pentingnya merencanakan jarak dan jumlah kelahiran menjadi titik awal bagi terbukanya kesejahteraan keluarga.

\section{Implementasi Konsep Collaborative Governance dalam Kebijakan Kampung KB di Kabupaten Jombang}

Keberhasilan Kampung KB di Kabupaten Jombang setidaknya dapat dilihat dari beberapa indikator ketercapaian model kampung KB. Indikator tersebut tidak semata-mata hanya melihat hasil, namun keberhasilan juga didasarkan pada input, proses dan output. Keberhasilan input ditandai dengan jumlah PLKB/ PKB proporsional, kuantitas dan kualitas IMP, ketersediaan dukungan operasional (anggaran) untuk program KKBPK dari APBD dan APBN maupun sumber dana lain seperti PNPM, Anggaran Dana Desa (ADD), ketersediaan alat kesehatan terkait dan alat kontrasepsi, Jamkesda, maupun sarana pendukung lain. Sedangkan 
Vol..5, No.2, 2019

Doi: https://doi.org/10.24198/cosmogov.v5i2.21814

http://jurnal.unpad.ac.id/cosmogov/index

indikator keberhasilan proses dalam ketercapaian kampung KB ditentukan oleh peningkatan frekuensi dan kualitas kegiatan advokasi dan KIE; Peningkatan kualitas pelayanan KB dan KR serta Pertemuan berkala kelompok kegiatan $\mathrm{BKB}, \mathrm{BKR}$, BKL, UPPKS dan pertemuan dalam mekop; Pelayanan Taman Posyandu, akta kelahiran. Sedangkan keberhasilan Output ditentukan terdiri dari indikator utama dan indikator penyerta/ pendukung. Indikator utama Kampung KB yakni :

1. Peningkatan persentase peserta $\mathrm{KB}$ aktif (PA) 65\% pada masa 3 tahun berjalan hingga 2019.

2. Peningkatan persentase keikutsertaan KB MKJP hingga $20 \%$.

3. Unmet need $<10 \%$

4. Keberlangsungan penggunaan alat kontrasepsi bagi pospartum dan pusmupar.

5. Terjangkaunya pelayanan kesehatan dan $\mathrm{KB}$ oleh ibu hamil dan menyusui.

6. Terjangkaunya pelayanan BKB bagi keluarga yang memiliki anak berusi 0-6 tahun.

7. Peningkatan keaktifan remaja dalam BKR dan PIK.

8. Peningkatan partisipasi keluarga pada kegiatan BKB/BKR/BKL/UPPKS.

9. Terjangkaunya pelayanan kesehatan bagi kelompok lansia (melalui Posyandu Lansia dan BKB)

10. Terjangkaunya pelayanan kesehatan bagi kelompok anak 
Vol..5, No.2. 2019

Doi: https://doi.org/10.24198/cosmogov.v5i2.21814

http://jurnal.unpad.ac.id/cosmogov/index

Selain itu, komitmen ini diperlukan untuk menjembatani berbagai sektor yang harus mengambil bagian dari implementasi program Kampung KB tersebut. Pasalnya, implementasi program Kampung KB ini tidak dilakukan sendiri oleh OPD terkait KB melainkan diperlukan sinergi dari berbagai OPD yang ada.

Kedua, integrasi program KKBPK dan sinergi lintas sektor. Secara substansi, tujuan Program KKBPK adalah perwujudan keluarga kecil yang bahagia dan sejahtera melalui pelaksanaan delapan fungsi keluarga. Pelaksanaan fungsi keluarga ini akan membantu keluarga menjadi lebih bahagia dan sejahtera, terbebas dari kemiskinan, kebodohan serta keterbelakangan.

Selain dapat membangun masyarakat melalui unit terkecil yakni keluarga, program Kampung KB juga dapat menyejahterakan serta memenuhi kebutuhan masyarakat melalui integrasi program lintas sektor. Integrasi dan kemitraan lintas sektor ini melibatkan peran berbagai pihak seperti swasta, provider, dan pemangku kepentingan lainnya. Salah satu contoh integrasi lintas sektor berupa pelayanan terpadu antar sektor yang menjadi kebutuhan masyarakat, seperti pelayanan $\mathrm{KB}$ oleh petugas kesehatan, pelayanan pembuatan ktp dan akta oleh petugas administrasi kependudukan, pembangungan jalan dan jembatan oleh dinas terkait, penyediaan buku-buku bacaan oleh perpustakaan dan juga swasta melalui CSR, pelaksanaan Posyandu dan PAUD oleh dinas terkait yang disupport masyarakat, P2WKSS dan lain-lain.

Ketiga, kolaborasi dalam pelaksanaan program ini juga dilaksanakan dengan penuh semangat dan dedikasi oleh para pengelola lapangan program KKBPK (PKB, IMP). Selain itu, kolaborasi enjadi lebih efektif karena ada dukungan berupa penyadaran terhadap masayrakat akan pentingnya program $\mathrm{KB}$ yang dilakukan oleh Instituasi Masyarakat Pedesaan (IMP), LSOM, lembaga swasta (CSO) serta tokoh masyarakat. Upaya tersebut dilakukan dengan partisipasi IMP bersama-sama PKB/PLKB dalam kegiatan kelompok seperti Bina-Bina keluarga (BKB, BKR, BKL, PIK-R dan UPPKS) serta kegiatan lain yang berada di tingkat Desa ke bawah, seperti kelompok kerja teknis (Pokjanis) KB-Kesehatan, Pendidikan dan Penerangan, serta Ekonomi produktif yang ada di Desa yaitu pada Lembaga Pembangunan Masyarakat Desa (LPMD), disamping itu juga dengan PKK Desa/Dusun terutama pada pokja IV PKK yang membidangi masalah $\mathrm{KB}$ dan Kesehatan.

Langkah pertama dari implementasi Collaborative Governance dimulai dengan penyusunan regulasi induk oleh kepala daerah. Regulasi ini merupakan political will yang menjadi payung terjadinya kolaborasi antar OPD terkait serta pelibatan masyarakat sipil dan sektor swasta dalam program ini. Dengan adanya regulasi ini, maka semua pihak akan dapat berpartisipasi dengan nyaman dan terarah. Selain itu, regulasi ini menjadi landasan hukum untuk segala aktivitas yang memerlukan pertanggung jawaban administrasi, misalnya, sumbangan buku atau alat kesehtan dari pihak swasta melalui 
Vol..5, No.2. 2019

Doi: https://doi.org/10.24198/cosmogov.v5i2.21814

http://jurnal.unpad.ac.id/cosmogov/index

program CSR, sharing pembiayaan dengan CSO, dan lain-lain.

Setelah regulasi ditetapkan, barulah dibentuk model Forum Guyub Kampung KB yang mempertemukan berbagai OPD dan pihak berkepentingan dalam Kampung KB seperti Pemerintah Desa, Masyarakat, Lembaga Swadaya Msyarakat (CSO) serta sektor swasta agar memudahkan koordinasi dan fasilitasi terhadap program yang telah dibuat. Dalam forum ini terjadi kesepakatan job discription antar masing-masing unsur agar dikemudian hari tidak lagi terdapat kendala koordinatif.

Pelibatan CSO dalam program Kampung KB ini penting dilakukan karena beberapa CSO memiliki program yang secara filosofi hampir sama, sehingga sinergi dengan mereka akan dapat mengurangi beban pemerintah dalam hal subtansi maupun materi. Sebut saja CSO Muslimat misalnya, badan otonom perempuan Nahdlatul Ulama ini memiliki anggota yang terorganisir dengan baik dari tingkat ranting atau setara desa hingga Pusat. Beberapa literatur menyebutkan bahwa Muslimat merupakan CSO perempuan yang paling kompak dan terorganisir dengan baik. Muslimat memiliki banyak kader di tingkatan desa yang banyak diantaranya merupakan tokoh masyarakat. Status tokoh masyarakat sebagai pihak yang mensosialisasikan program diperlukan agar masyarakat dapat menerima program dengan baik. Selain itu internalisasi pemahaman akan pentingnya program akan lebih mudah dilakukan oleh orang yang sudah dikenal dan disegani. Ada pula WCC (Women Crisis Center)
Jombang yang telah banyak melakukan advokasi dan program pemberdayaan perempuan dan keluarga. Pelibatan WCC dalam program ini dirasa sangat tepat karena kesamaan filosofi program dan tujuan.

Peran sektor swasta pun tidak bisa dianggap remeh dalam keberhasilan program Kampung KB. Beberapa perusahan, misalnya PT. CGI, Pabrik Gula Jombang Baru dan BRI telah mendukung pelaksanaan program melalui program CSR yang berupa pelatihan keterampilan dalam rangka pemberdayaan masyarakat penyediaan bibit tumbuhan untuk program KRPL (Kawasan Rumah Pangan Lestari).

Baiknya kolaborasi yang dilakukan oleh pemerintah, masyarakat sipil (CSO dan masyarakat), serta sektor swasta inilah yang kemudian membuat implementasi program Kampung KB di Kab. Jombang mencapai target.

\section{SIMPULAN}

Peningkatan kualitas hidup masyarakat di tingkat kampung diharapkan akan dapat dicapai melalui program Kampung KB. Sebagai miniatur pembangunan yang melibatkan partisipasi seluruh elemen masyarakat, Kampung KB sebagai implementasi program KKBPK telah berhasil mengejawantahkan konsep Collaborative Governance. Indikator keberhasilan Kampung KB terhadap program KKBPK meliputi peningkatan jumlah akseptor KB baru, terlayaninya kesehatan ibu hamil dan menyusui, remaja aktif dalam kegiatan BKR dan PIK, penurunan angka buta aksara, peningkatan partisipasi keluarga pra sejahtera dan KS-1 
Vol..5, No.2, 2019

Doi: https://doi.org/10.24198/cosmogov.v5i2.21814

http://jurnal.unpad.ac.id/cosmogov/index

dalam program UPPKS. Hasil kajian di 4 lokasi kampung KB di Kabupaten Jombang yakni Dusun Munggut, Desa. Cupak, Kecamatan. Ngusikan; Dusun. Sumberpelas, Desa. Plabuhan, Kecamatan. Plandaan; Dusun. Pulonasir, Desa. Pulosari, Kecamatan. Bareng; Dusun. Tegalrejo, Desa. Jarak, Kecamatan. Wonosalam; Dusun. Kepuh, dapat disimpulkan bahwa keberadaan kampung KB sejak dicanangkan tahun 2016 cukup berkontribusi pada beberapa indikator Program KKBPK seperti peningkatan angka pengguna akseptor KB baru yang mayoritas terjadi di seluruh lokasi Kampung KB. Selain itu pelayanan kesehatan ibu hamil dan menyusui yang ditandai dengan tidak adanya lagi angka kematian ibu dan bayi di seluruh lokasi tersebut juga mengalami penngkatan cukup baik. Namun masih ada beberapa hal yang perlu ditingkatkan, yakni masih kurangnnya fasilitas kesehatan di tingkat dusun, partisipasi aktif remaja dalam kegiatan BKR dan PIK di setiap program yang ada serta penggenjotan lagi penurunan angka buta aksara. Selain itu masih ada satu indikator yang belum mengalami perubahan secara signifikan meski implementasi kampung KB berjalan hampir 2 tahun yakni belum maksimalnya program-program UPPKS di 4 lokasi kampung KB tersebu. Hal ini terjadi akibat

\section{DAFTAR PUSTAKA}

Badan Kependudukan Keluarga Berencana Nasional, 2015. Petunjuk Teknis Kampung KB. Jakarta: BKKBN

Christensen, T., \& Lla egreid, P. 2006. The whole-ofgovernment approachregulation, performance, and public-sector reform. Retrieved tidak adanya modal untuk UPPKS, minimnya pengetahuan untuk menciptakan program serta rendahnya kesadaran maupun partisipasi masyarakat dalam program UPPKS.

Berdasarkan realita yang tertangkap oleh kajian ini, maka rekomendasi kebijakan yang dapat diformulasikan dengan Konsep Collaborative Governance antara lain:

Memasukkan program Kampung KB dalam Rencana Anggaran Pendapatan dan Belanja Desa. Hal ini dilakukan untuk menjamin keberlangsungan program. Selain itu, ini juga merupakan bukti dari komitmen pemerintah dalam menjaga keberlangsungan program. Agar dapat diimplementasikan secara cepat dan merata, diperlukan regulasi berupa Peraturan Bupati yang menjadi payung dari rencana ini.

Pembentukan sebuah Forum yang dapat dijadikan sebagai sarana koordinasi antar Kampung KB, misalnya "Guyub Kampung KB'. Forum ini selain sebagai wadah bersama Kampung KB, juga dapat dimanfaatkan sebagai wadah sinergisitas antar stakeholder yang ada seperti OPD, Kecamatan, Pemerintah Desa, CSO, sektor swasta hingga Masyarakat agar memudahkan koordinasi dan fasilitasi terhadap program yang telah dibuat.

from

http://bora.uib.no/handle/1956/189 3

Mardiyono, 2017. Kampung KB sebagai Upaya Pemberdayaan Masyarakat / Keluarga di Jawa Timur. Jurnal Cakrawala Vol. 11 No. 2 Desember 2017: p 129-136 
Vol..5, No.2, 2019

Doi: https://doi.org/10.24198/cosmogov.v5i2.21814

http://jurnal.unpad.ac.id/cosmogov/index

Prijono Onny S., \& A.M. W. Pranaka, 1996. Pemberdayaan: Konsep, Kebijakan dan Implementasi. Jakarta: Center for Strategic and International Studies.

Sugiyono. 2015. Metode Penelitian Kuantitatif, Kualitatif dan R \& D. Bandung: Alfabeta.

Shergold, P., \& others. 2004. Connecting government: Governance Collaborative Australia"s responses to challenges.[Launching speech made on 20 April 2004.]. Canberra Bulletin of Public Administration, (112), 11.

Zultha, Nurhafifah. 2017. Implementasi Program Kampung KB dalam Upaya Penanggulangan Kemiskinan. Lampung: Universitas Lampung
Profil Kampung KB Dusun Munggut, Desa Cupak, Kecamatan Ngusikan, Kabupaten Jombang

Profil Kampung KB Dusun Sumberpelas, Desa Plabuhan, Kecamatan Plandaan, Kabupaten Jombang

Profil Kampung KB Dusun Pulonasir, Desa Pulosari, Kecamatan Bareng, Kabupaten Jombang

Sensus Penduduk Tahun 2010 Badan Pusat Statistik

Undang-undang No. 52 tahun 2009 tentang Perkembangan Kependudukan dan Pembangunan Keluarga. Pasal 3 ayat (a) \& (b)

Kampung KB wujud Konkret People Centered Devolepment, Majalah Warta Kencana Edisi 12 halaman 8-9 Tahun IV /April 2013. 